Pirineos. Revista de Ecología de Montaña

Vol. 171

Jaca, Enero-Diciembre, 2016, e022

ISSN-L: 0373-2568

doi: http://dx.doi.org/10.3989/Pirineos.2016.171006

\title{
LA EVOLUCIÓN DEL PISO SUBALPINO EN LA SIERRA DE URBIÓN (SISTEMA IBÉRICO, NORTE DE ESPAÑA): UN MODELO DE IMPACTO GEOECOLÓGICO DE ACTIVIDADES HUMANAS EN EL VALLE DE ORMAZAL
}

\section{Evolution of the subalpine belt in the Urbion Sierra (Iberian Range, Northern Spain): an example of the geoecological impact of human activity in the Ormazal Valley}

José M. García-Ruiz * , Yasmina Sanjuán¹, José Arnáez², Santiago Beguería³, Amelia Gómez-Villar, Javier Álvarez-Martínez ${ }^{5}$, Noemí Lana-Renault ${ }^{3}$, Paz Coba-Pérez ${ }^{6}$

${ }^{1}$ Instituto Pirenaico de Ecología, Consejo Superior de Investigaciones Científicas (IPE-CSIC), Campus de Aula Dei, Apartado 13.034, 50.080-Zaragoza, Spain. 2 Área de Geografía Física (DCH), Universidad de La Rioja, 26.004-Logroño, Spain.

${ }^{3}$ Estación Experimental de Aula Dei, Consejo Superior de Investigaciones Científicas (EEAD-CSIC), Campus de Aula Dei, Apartado 13.034, 50.080-Zaragoza, Spain. ${ }^{4}$ Departamento de Geografía y Geología, Facultad de Filosofía y Letras, Universidad de León, Campus de Vegazana, 24.071-León, Spain.

${ }^{5}$ Departamento de Ingeniería Agrícola y Forestal, Universidad de Valladolid, Campus La Yutera, 34.071-Palencia, Spain.

${ }^{6}$ Centro de Investigaciones en Geografía Ambiental, CIGA, Universidad Nacional Autónoma de México, UNAM, Antigua Carretera a Pátzcuaro 8701, Col. Ex Hacienda San José de la Huerta, 58190-Morelia, Michoacán, México.

*Autor corresponsal

Recibido: 04-06-2016. Aceptado: 24-06-2016. Fecha de publicación on-line: 07/09/2016

Citation / Cómo citar este artículo: García-Ruiz, J. M., Sanjuán, Y., Arnáez, J., Beguería, S., Gómez-Villar, A., ÁlvarezMartínez, J., Lana-Renault, N., Coba-Pérez, P. (2016). La evolución del piso subalpino en la Sierra de Urbión (Sistema Ibérico, norte de españa): un modelo de impacto geoecológico de actividades humanas en el Valle de Ormazal. Pirineos, 171 , e022. doi: http://dx.doi.org/10.3989/Pirineos.2016.171006

RESUMEN: Este trabajo es una síntesis de la evolución paisajística, funcional y geomorfológica del piso subalpino de la Sierra de Urbión, proporcionando una perspectiva geoecológica de las interacciones entre actividades humanas, organización del espacio, dinámica geomorfológica y transformaciones recientes en los usos del suelo. Los cambios paisajísticos del piso subalpino en la Sierra de Urbión se iniciaron al menos en el Neolítico tardío con incendios que procuraban eliminar el bosque para permitir la expansión de los pastos de aprovechamiento estival y así favorecer una incipiente trashumancia de ganado lanar. Los incendios se prolongaron a lo largo del Calcolítico y las edades del Bronce y del Hierro, culminando durante la Edad Media. Es probable que en este último periodo los incendios fueran menos necesarios dados los cambios producidos anteriormente. La deforestación del piso subalpino sería responsable de la ocurrencia de numerosos deslizamientos, que han desmantelado el suelo en gran parte de la Sierra por encima de 1500 m s.n.m. La crisis del sistema trashumante a partir de comienzos del siglo xIX ha reducido la presión ganadera sobre los pastos de verano y, especialmente en la segunda mitad del siglo xx, ha contribuido a la expansión de matorrales y bosques, mientras los pastos subalpinos se han reducido notablemente. El descenso de la presión ganadera indica que la expansión del bosque va a continuar en el futuro, en un contexto de calentamiento global y menor duración del manto de nieve en el piso subalpino. 
PALABRAS CLAVE: Piso subalpino; Geoecología; Deslizamientos superficiales; Incendios forestales; Paisaje; Abandono de tierras; Expansión del bosque.

\begin{abstract}
This paper is a synthesis of the landscape, geomorphic and functional evolution of the subalpine belt in the Urbión Sierra, providing a geoecological perspective of the interactions between human activity, spatial organization, geomorphological dynamics and recent land use changes. Landscape changes in the subalpine belt started at least during the Late Neolithic, with forest fires that tried to waste the forest to enable the expansion of summer grasslands favouring an incipient sheep transhumance. Fires occurred also through the Chalcolithic and the Bronze and Iron Ages, and culminated during the Middle Ages. Deforestation of the subalpine belt would be responsible for the triggering of a number of shallow landslides and soil erosion in steep slopes above $1500 \mathrm{~m}$ a.s.1. The crisis of the transhumance since the beginning of the 19th century reduced the livestock pressure, particularly in the second half of the 20th century, and has contributed to shrub and forest expansion, whereas the area occupied by summer grasslands has been remarkably reduced. The decreasing livestock pressure suggests that forest expansion will continue in the next future, in a favourable context of global warming and declining presence of snowpack in the subalpine belt.
\end{abstract}

KEYWORDS: Subalpine belt; Geoecology; Shallow landslides; Forest fires; Landscape; Land abandonment; Forest expansion.

\section{Introducción}

Es bien sabido que la explotación del territorio en áreas de montaña se basa en el aprovechamiento integrado de los diferentes pisos altitudinales, dando lugar a un sistema complejo en el que cada una de las unidades de paisaje se halla íntimamente relacionada con las demás, formando un conjunto indisoluble en el que todos sus elementos son interdependientes (Puigdefábregas \& Fillat, 1986; García-Ruiz et al., 2015). El aprovechamiento tradicional de los recursos y la construcción de los paisajes de montaña han sido la consecuencia de un proceso generalmente muy lento, a veces con saltos hacia atrás debido a crisis climáticas, demográficas y/o políticas, para tratar de obtener el máximo beneficio posible en función de una determinada organización social frente a las limitaciones del medio, especialmente las fuertes pendientes y los condicionantes climáticos (Puigdefábregas \& Balcells, 1970; Montserrat, 2009).

Las montañas europeas (y las de la Península Ibérica no son una excepción) se han visto afectadas por la deforestación del piso montano inferior para la creación del espacio agrícola destinado a la alimentación de la población humana, ocupando primero los mejores lugares desde un punto de vista topográfico (terrazas fluviales, pies de vertiente, conos de deyección parcialmente inactivos $\mathrm{y}$, quizás, algunos rellanos colgados: antiguos lagos de obturación glaciar rellenos de sedimento). No obstante, el crecimiento demográfico obligó a ocupar laderas más pendientes, unas veces mediante bancales y otras con campos en pendiente sin apenas alteración de la topografía (Lasanta, 1989, 2014). En situaciones excepcionales, durante el máximo demográfico de mediados del siglo XIX o como consecuencia de crisis político-económicas, se ocuparía buena parte del piso montano, hasta el límite que permitía la producción de cereales (generalmente centeno), que en las montañas del norte de la Península Ibérica estuvo entre 1450 y 1650 m s.n.m., umbral a partir del cual la integral térmica es insuficiente para permitir una cosecha. Algunos campos, muy alejados de los nú- cleos de población o en pendientes muy fuertes, se cultivaron durante unos pocos años, quizás tres o cuatro, hasta que se agotaron o se degradaron y posiblemente volvieron a cultivarse 25 o 30 años después, dentro de un sistema de agricultura nómada que fue habitual en las montañas de la Península Ibérica hasta la primera mitad del siglo xx (Ruiz-Flaño, 1993; Lasanta et al., 2006). De esta forma, el bosque del piso montano fue una especie de reserva, unas veces de capital para obtener rentas mediante la venta de madera, y otras veces de tierra para cultivar laderas en momentos de mayor presión demográfica. En todo caso, se trata de un espacio fluctuante, poco estable en el tiempo, en el que la presencia de masas forestales y de campos de cultivo mostraría una notable dinámica.

El piso subalpino ha tenido una función muy relevante en la organización del espacio de las montañas europeas (e.g., Daumas, 1976; Lasanta, 1990; García-Ruiz \& Lasanta, 1993). Seguramente, la deforestación del piso subalpino (<1600 m s.n.m.) ocurrió paralelamente a la del piso montano (800-1600 m), con el fin de favorecer la expansión de pastos de aprovechamiento estival que serían la base de la ganadería trashumante (Puigdefábregas \& Balcells, 1966). Un creciente número de estudios basados en el análisis de sedimentos de turberas y lagos de alta montaña ayudan a identificar e interpretar los estadios principales de la conversión de los bosques subalpinos en pastos. Es el caso, por ejemplo, de los trabajos de Montserrat (1992), Galop \& Jalut (1994), Miras et al. (2007, 2010), Bal et al. (2011) y Pérez-Sanz et al. (2013) en el Pirineo Central español, así como los de Tinner et al. (2003), Blarquez et al. (2009), Colombaroli et al. (2010, 2013), Guiguet-Covex et al. (2011) y Roepke \& Krause (2013) en los Alpes. En los macizos del noroeste del Sistema Ibérico (norte de España) los estudios llevados a cabo en sedimentos de turberas también apuntan hacia la transformación del piso subalpino desde hace unos 5000 años, con un retroceso del bosque (por ejemplo, Gil García et al., 1995, 1996, 2002). De igual forma, la presencia de dólmenes (aunque situados por debajo del umbral inferior del piso subalpino) muestra el desarrollo de socieda- 
des agropastoriles desde el Neolítico (López de Calle \& Pérez Arrondo, 1995; López de Calle et al., 2001; López de Calle \& Tudanca, 2014). Los cambios que se han producido en el piso subalpino a lo largo de los últimos milenios han provocado el descenso altitudinal de la treeline en unos 500 metros, y la desaparición casi completa del krummholz (zona superior del piso subalpino, donde los árboles aparecen deformados por el viento y la prolongada presencia de nieve), favoreciendo la ocurrencia de numerosos procesos erosivos, solifluxión (Höllermann, 1985) y deslizamientos superficiales (García-Ruiz et al., 2010). Sin embargo, es preciso tener en cuenta que el mantenimiento de un paisaje dominado por la presencia de pastos en el piso subalpino sólo ha sido posible mediante la fuerte presión ganadera, que limitaba la recolonización por parte de matorrales y arbolado (Gartzia et al., 2016), así como por la utilización relativamente frecuente del fuego. La relajación reciente de esa presión ganadera ha creado un nuevo escenario caracterizado por la expansión de especies leñosas en un contexto de incremento térmico que pudiera estar acelerando el proceso.

Este trabajo se centra en el piso subalpino de la Sierra de Urbión (noroeste del Sistema Ibérico), y en particular en el valle de Ormazal, en un intento por integrar la información existente sobre actividades humanas, cambios de cubierta vegetal y evolución geomorfológica en un espacio extremadamente dinámico, marcado históricamente por la fuerte presencia de ganado durante el verano. Esta evolución incluye desde la deforestación en el Neolítico y periodos posteriores (García-Ruiz et al., 2016) hasta la recuperación reciente de la cubierta forestal (Sanjuán et al., enviado), pasando por la ocurrencia de numerosos deslizamientos y otros procesos erosivos como consecuencia del crecimiento demográfico y de la actividad humana (Beguería et al., enviado). Dada la intensidad de los cambios que se han producido en la Sierra de Urbión, se trata de un excelente ejemplo de las interacciones entre aprovechamiento del territorio, dinámica de la vegetación y procesos geomorfológicos.

\section{2. Área de estudio}

La Sierra de Urbión es una de las más elevadas del Sistema Ibérico, en el norte de España, alcanzando su máxima altitud a 2228 m s.n.m. (Figura 1). Se compone principalmente de microconglomerados cuarcíticos o cuarzoarenitas y arcillas rojas y calizas del Jurásico Superior y del Cretácico Inferior, correspondientes a un gran paleodelta (Tischer, 1966). La tectónica alpina deformó y fracturó estos materiales, dando lugar a un relieve monoclinal con la vertiente abrupta mirando al norte. Esta vertiente fue afectada por el glaciarismo pleistoceno, que dejó valles en artesa de hasta 6-7 km de longitud, lagos de sobreexcavación glaciar, rellanos laterales de obturación, circos y depósitos morrénicos. Estos últimos descienden hasta 1270 m s.n.m. (García-Ruiz et al., 1998).

El clima es mediterráneo de montaña, con tendencias húmedas. Los únicos datos disponibles proceden de observatorios localizados en la vertiente meridional de la

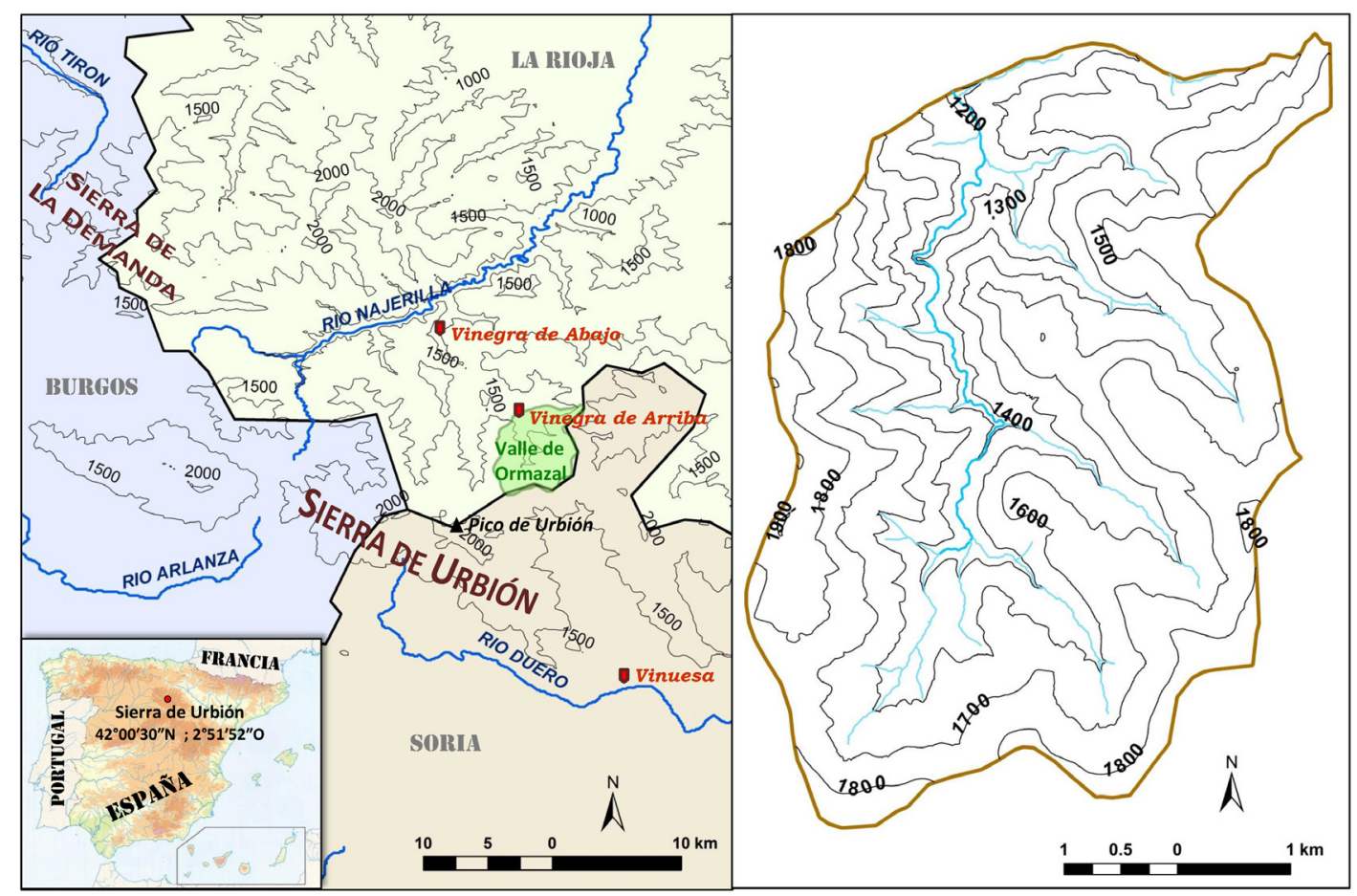

Figura 1: La Sierra de Urbión con la localización del valle de Ormazal. A la derecha, el valle de Ormazal. Figure 1: The Urbión Sierra with the location of the Ormazal Valley. Right, the Ormazal Valley. 
Sierra entre 1100 y $1150 \mathrm{~m}$ de altitud, con un registro de $9,6^{\circ} \mathrm{C}$ en Vinuesa para el periodo 1990-2001 (García de Celis et al., 2008). La precipitación media anual supera los $900 \mathrm{~mm}$ por encima de $1000 \mathrm{~m}$ s.n.m. y probablemente está por encima de $1500-1600 \mathrm{~mm}$ en la divisoria principal, de acuerdo con las estimaciones de Arnáez Vadillo (1987) para la vecina Sierra de la Demanda.

La cubierta vegetal está dominada por extensos bosques de Pinus sylvestris en la vertiente meridional, mientras en la septentrional tiene lugar un mosaico más complejo en el que destacan bosques de P. sylvestris y Fagus sylvatica (estos últimos por debajo de $1500 \mathrm{~m}$ s.n.m.) y extensos pastizales ocasionalmente invadidos por $\mathrm{Vacci}$ nium myrtillus y brezales de Calluna vulgaris y Erica cinerea incluso en suelos sobre sustrato calizo, junto a ejemplares aislados de Juniperus communis.

El piso subalpino de la Sierra de Urbión y parte del piso montano superior han sido intensamente utilizados por el ganado ovino trashumante, muy probablemente desde el Neolítico (ver apartado 3). Es casi seguro que el número de rebaños trashumantes aumentó notablemente desde la Edad Media, alcanzando periodos de auge en el siglo XV y entre el final del siglo XVII y el del siglo XVIII, coincidiendo con el aumento internacional en la demanda de lana (Diago Hernando, 2002). El sistema trashumante sufrió, sin embargo, una aguda crisis a comienzos del siglo XIX, lo que explica la expansión del espacio cultivado (Moreno Fernández, 1994). En 1792 el número de cabezas de ganado lanar era de 17.169 (262 por $\mathrm{km}^{2}$ ) en Viniegra de Abajo, y de 19.100 (497 por $\mathrm{km}^{2}$ ) en Viniegra de Arriba (Moreno Fernández, 1996). La decadencia ganadera ha continuado hasta la actualidad, cuando se contabilizan 840 y 2690 cabezas respectivamente. La población también se ha reducido mucho en ambas localidades: Viniegra de Abajo tenía 689 habitantes en 1842 y 97 en 2011, mientras Viniegra de Arriba tenía 418 habitantes en 1842 y 40 en 2011.

El estudio, enmarcado en la Sierra de Urbión, se ha centrado en el valle de Ormazal, con una extensión de 2513,8 ha y un rango altitudinal entre 1240 y $1887 \mathrm{~m}$ s.n.m. En su parte inferior presenta algunos campos de cultivo ya abandonados, mientras el resto del valle forma un paisaje muy diversificado con bosques, pastos subalpinos y matorrales en un territorio de pendientes relativamente suaves $(<30 \%$ en general) y divisorias amplias.

\section{Primeras evidencias de actividades humanas: La deforestación}

García-Ruiz et al. (2016) dataron ocho fragmentos de carbones encontrados en perfiles de suelos del piso subalpino de la Sierra de Urbión, entre 1738 y 1859 m s.n.m. El procedimiento de datación utilizado fue AMS (Accelerator Mass Spectrometry) y los resultados fueron calibrados utilizando Calb v. 7.02 (Stuiver \& Reimer, 1993) y las más recientes bases de datos de calibración (Reimer et al., 2013). Los resultados obtenidos demuestran que la actividad humana en alta montaña se remonta al Neolítico tardío (5630 cal años BP), cuando se consolida el asentamiento de poblaciones estables a altitudes medias y bajas (López de Calle \& Pérez Arrondo, 1995; López de Calle $\&$ Tudanca, 2014) y se hace necesario subir con el ganado a los pastos más frescos de alta montaña en verano. También se han datado incendios durante el Calcolítico (4911, 4858 y 3962 cal años BP), durante la Edad del Bronce (3162 cal años BP), la Edad del Hierro (2234 y 2034 cal años BP) y la Edad Media (1116 cal años BP) (GarcíaRuiz et al., 2016). Esto quiere decir que el proceso de transformación del piso subalpino de bosque a pastos de verano tuvo lugar de manera más o menos continua desde el Neolítico hasta la Edad Media.

No está claro cómo ocurrió la deforestación. Sabemos de la utilización del fuego, pero no tenemos más información sobre un aspecto que sería clave para explicar la evolución del piso subalpino inducida por actividades humanas. Por ejemplo, no disponemos actualmente de datos para discernir si la deforestación ha sido un proceso lento, más bien relacionado con el progresivo incremento en el número de cabezas de ganado o si ocurrió de manera brusca en las primeras etapas del pastoreo. Parece más lógica la segunda opción: una vez iniciado un incendio, sería difícil su control. Por otro lado, los pastores no sólo estarían interesados en la creación de áreas de pastos; también lo estarían por despejar el campo de visión y asegurar el control del territorio frente a otros posibles competidores (personas y animales). En ese caso, durante las primeras etapas de ocupación humana del piso subalpino, el bosque reocuparía frecuentemente las áreas de pastos de forma natural, debido a la baja presión ganadera en ausencia de mercados locales o regionales importantes. Eso explicaría la frecuencia de incendios que se han detectado hasta la Edad del Hierro, ya en el inicio de la dominación romana. Durante la Edad Media, cuando la trashumancia inicia una marcada expansión, y durante la Edad Moderna, cuando los rebaños de ganado lanar alcanzarían sus cifras más elevadas, no hay apenas nuevas fechas de incendios. Esto puede interpretarse como la consecuencia de la evolución anterior: parte del piso subalpino habría sido previamente deforestado y sólo serían necesarios incendios más locales. Cabe, no obstante, plantearse una hipótesis que no hemos podido desarrollar: si no se han encontrado más restos de carbones correspondientes a la Edad Media y ninguno de la Edad Moderna, a pesar de coincidir con el momento de mayor presión ganadera, es muy probable que se deba al hecho de no haber prospectado en los lugares adecuados. La expansión ganadera desde el siglo xv podría explicar la deforestación no tanto del piso subalpino, que ya se habría alcanzado en periodos anteriores, sino de parte del piso montano superior (entre 1450 y 1650 m s.n.m.), que hasta entonces no habría sido necesario ocupar. El problema es que nuestra prospección se centró exclusivamente en el piso subalpino, porque estuvo vinculada a la presencia de cicatrices de deslizamientos, que fundamentalmente aparecen en ese piso.

¿Cómo era el paisaje del piso subalpino en la Sierra de Urbión durante la máxima expansión ganadera? No hay información directa, aunque muy probablemente la 
deforestación afectaría a casi todo el territorio por encima de 1450 o 1500 m s.n.m., con ausencia general de arbolado. La Figura 2A muestra la distribución del bosque (denso y abierto) y del matorral en el valle de Ormazal en 1956, cuando la crisis de la trashumancia se había anunciado abiertamente. Esta figura refleja la presencia de muy escasas y reducidas manchas de bosque denso (básicamente compuesto por frondosas), acantonadas sobre todo en el norte del valle, en torno a 1300 m s.n.m. Las manchas de bosque claro aparecen dispersas en el centrooeste del valle entre 1500 y $1800 \mathrm{~m}$, y en la parte más meridional, siempre junto a manchas más extensas de matorral. Esta distribución sugiere la ocurrencia de un proceso de recuperación del matorral y, más secundariamente, del bosque como consecuencia del descenso de la presión ganadera que se anunciaba ya desde el siglo XIX (Moreno Fernández, 1994). El resto del mapa corresponde a áreas de pastos de aprovechamiento estival y zonas erosionadas, que, como veremos en el siguiente apartado, corresponderían a zonas ocupadas previamente por bosques y pastos. Es importante tener en cuenta que los pastos subalpinos son los que ocupaban una mayor superficie (36,2\%), seguidos por las áreas de matorral $(33,9 \%)$, mientras el bosque claro representaba sólo el $9,2 \%$, el bosque denso, el 1,7\%, y las áreas erosionadas, el 16,1\% (Sanjuán et al., enviado). De ahí cabe deducir que en el momento de máximo auge de la trashumancia (algo más de un siglo antes) casi todo el valle de Ormazal estaría ocupado por pastos subalpinos o por áreas erosionadas que con casi total seguridad proceden del desmantelamiento del suelo tras la deforestación.

\section{La crisis de la trashumancia y la recuperación del bosque}

Los pueblos del Sistema Ibérico riojano (Urbión, Demanda, Cebollera y los altos valles del Cidacos y Alhama) han practicado de forma general la trashumancia de ganado lanar, que, por razones históricas, se llevaba a cabo desde la Reconquista hacia las tierras del sur y suroeste de España (Calvo Palacios, 1977; Rodríguez Pascual, 2004). La trashumancia permitía ampliar el tamaño de los rebaños y optimizar el aprovechamiento de pastos en dos ambientes complementarios, las áreas de montaña y las tierras llanas. Esto tuvo muchas consecuencias desde el punto de vista de la organización social y los modos de vida de los pueblos de montaña (véase Esteva Fabregat, 1971; Pujadas \& Comas, 1975). También tuvo consecuencias ambientales al forzar la explotación de los pastos subalpinos y al contribuir a la diversidad paisajística no sólo en la montaña, sino también en las zonas adehesadas del sur y suroeste de España. Pero era un sistema extremadamente complejo desde un punto de vista socioeconómico, que sólo era sostenible bajo determinadas condiciones de estabilidad dentro y fuera del sistema, in-
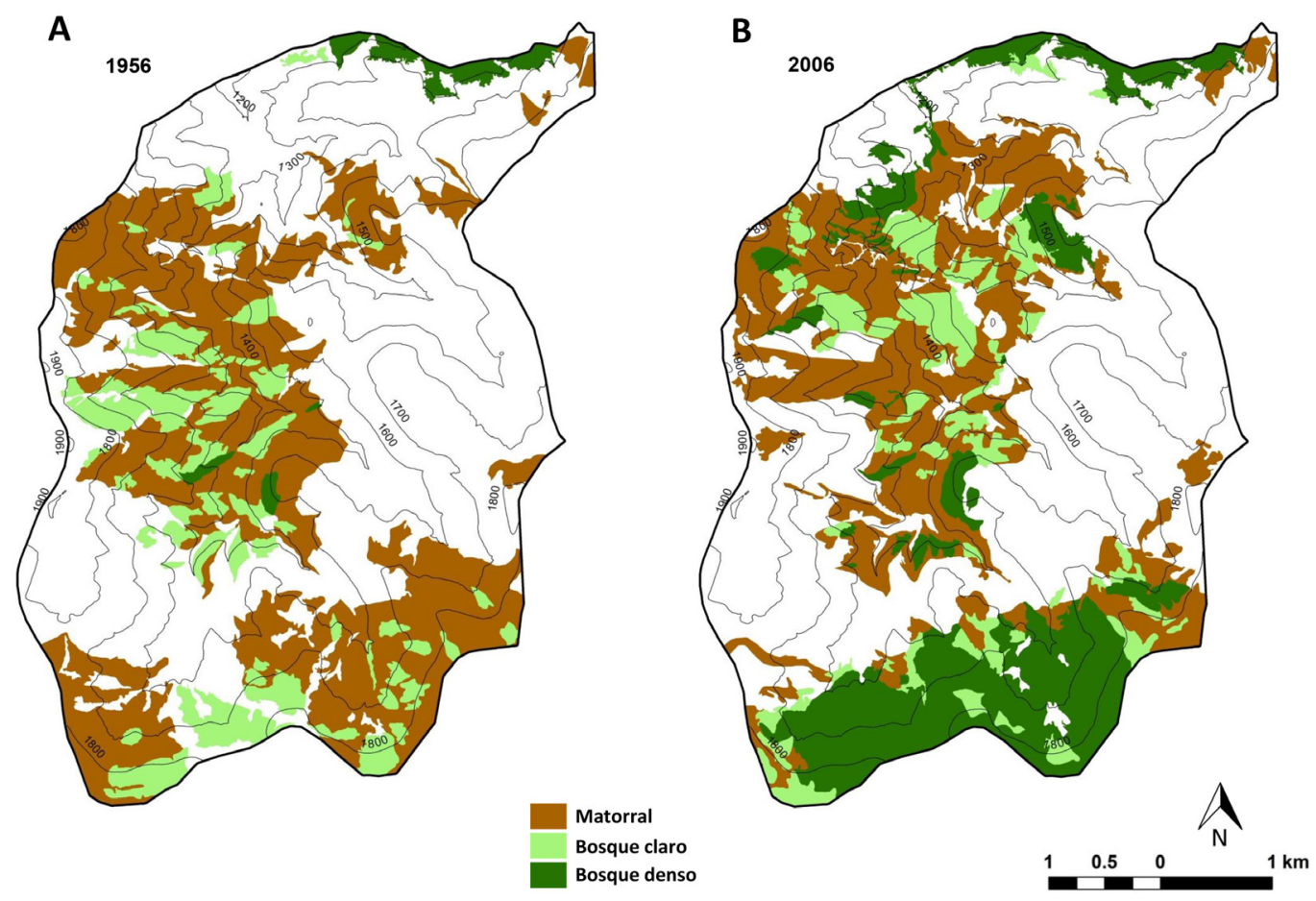

Figura 2: Distribución de matorrales, bosque claro y bosque denso en el valle de Ormazal. A: A partir de fotografías aéreas de 1956. B: A partir de las ortofotos de 2006.

Figure 2: Spatial distribution of shrublands, clear forest and dense forest in the Ormazal Valley. A: From aerial photographs of 1956. B: From orthophotos of 2006. 
cluyendo sobre todo la abundancia de mano de obra muy barata y la fuerte jerarquización social (Esteva Fabregat, 1971; García-Ruiz, 1976). Bastarían cambios en el mercado de la lana (Diago Hernando, 2002) o en el mercado de trabajo en los centros urbanos para que este sistema se desmoronase en unas pocas décadas (García-Ruiz, 2009a). La emigración, anunciada desde finales del siglo XIX y acentuada entre 1950 y 1970, se llevó consigo la organización social y privó de mano de obra al desplazamiento del ganado y al pastoreo, especialmente en las tierras bajas. Desde entonces la trashumancia se convirtió en un sistema de aprovechamiento anecdótico y casi desaparecido. La consecuencia más inmediata, que ya se manifestó desde el siglo XIX, fue el descenso acusadísimo de los censos de ganado lanar $\mathrm{y}$, como solución alternativa, la expansión (no compensatoria por diferentes motivos) de los censos de ganado vacuno. Este proceso ha ocurrido en todas las montañas españolas y es irreversible en las actuales circunstancias socioeconómicas, a pesar de que representa un abandono de recursos pastorales, la pérdida de una cultura que interpretaba muy ajustadamente los ciclos de la naturaleza, y la transformación del paisaje cuya funcionalidad se encamina por derroteros bien diferentes.

La Figura 2B muestra la distribución de matorrales, bosque claro y bosque denso en el año 2006, cincuenta años después de la representación de estas formaciones vegetales en 1956 (Figura 2A). Muchos son los cambios que se han producido y todos tienen que ver con el descenso de la presión ganadera, que favoreció la expansión de especies leñosas. Llama la atención, sobre todo, la presencia de una extensa mancha de bosque denso dominado por $P$. sylvestris en la parte meridional del valle de Ormazal, donde en 1956 sólo había matorrales y pequeños pinares aclarados. El bosque también está ampliándose en el sector centro-occidental del valle, donde las manchas de bosque claro son más extensas, y aparecen algunas áreas colonizadas por pinares densos, todo ello a costa de las formaciones de matorral que, sin embargo, se han extendido hacia el norte. En no pocos casos, la ampliación del bosque se ha producido también a costa de pastos subalpinos, que también se han visto ocasionalmente invadidos por el matorral (Sanjuán et al., enviado). Las cifras son bien elocuentes: los bosque densos, que en 1956 ocupaban el 1,7\% del territorio, han pasado al 17,4\%, mientras el matorral y los pastos subalpinos representan ahora el $25,9 \%$ y el $27,1 \%$, respectivamente. Es interesante tener en cuenta que la altitud media del bosque denso era de $1448 \mathrm{~m}$ en 1956 y de $1638 \mathrm{~m}$ en 2006, es decir, un avance altitudinal de casi 200 m (Sanjuán et al., enviado), mientras que los matorrales descendieron en altitud media y los pastos subalpinos se mantuvieron sin cambios.

\section{Las consecuencias geomorfológicas de la deforestación}

La mera observación del piso subalpino en la Sierra de Urbión muestra que la deforestación ha tenido elevados costes desde un punto de vista geomorfológico. Son numerosos los deslizamientos superficiales que afectan al suelo. Éste, a su vez, presenta una notable variabilidad en cuanto a su espesor debido a la redistribución llevada a cabo por tales deslizamientos y por solifluxión. Por otro lado, las zonas de pastos coexisten con extensas áreas erosionadas que ocupan espacios de características ambientales similares (Figuras 3, 4 y 5). Es decir, tal como se evidenció en el piso subalpino del Pirineo centro-occidental, la sustitución de bosque por pastos activó procesos de erosión que no están presentes bajo la cubierta forestal. De hecho, Höllermann (1985) señaló que la deforestación del piso subalpino en el Pirineo representó un descenso altitudinal de la solifluxión en unos 400 metros. Los deslizamientos superficiales son también un fenómeno muy común en el subalpino pirenaico (GarcíaRuiz et al., 1990, 2010), como consecuencia de la pérdida de la cohesión que aportaban las raíces, por el mayor consumo de agua por parte del arbolado y por el efecto de la interceptación, que reduce la cantidad de agua que llega al suelo bajo cubierta forestal (Serrano-Muela et al., 2008). La formación de incisiones paralelas que cubren laderas enteras es otro fenómeno habitual en el subalpino pirenaico (García-Ruiz \& Puigdefábregas, 1982).

En total, 307 deslizamientos superficiales han sido inventariados en el valle de Ormazal, es decir, una media de 12,2 deslizamientos por $\mathrm{km}^{2}$, el 95,8\% de los cuales está por encima de $1500 \mathrm{~m}$ s.n.m. y sobre todo entre $1700 \mathrm{y}$ $1800 \mathrm{~m}$, es decir, en pleno piso subalpino. Cada deslizamiento consta de una cicatriz semicircular u ovalada que deja ver las características del suelo (Kastanozem de color oscuro y estructura granular en el horizonte A, mientras los horizontes $\mathrm{B}$ y $\mathrm{C}$ tienen un color pardo amarillento y estructura de angular a sub-angular), con un espesor medio de 40 a $70 \mathrm{~cm}$ y con una clara diferenciación de horizontes A, B y C (Beguería et al., enviado). En el frente de la cicatriz puede encontrarse parte del material deslizado, aunque es frecuente que éste haya sido arrastrado ladera abajo. La zona deslizada muestra la presencia de terracillas de soligelifluxión en el caso de que haya quedado algún resto de suelo o, más habitualmente, la superficie del sustrato rocoso que hace las veces de plano de deslizamiento.

El estudio de Beguería et al. (enviado) demuestra la estrecha relación de dependencia de los deslizamientos respecto de la cubierta vegetal. La Figura 6 muestra la distribución de los pastos subalpinos y de las áreas erosionadas en 2006. Se incluye también la localización de las cicatrices de deslizamientos, que muestran una distribución bastante agrupada. De los 307 deslizamientos identificados en el valle de Ormazal, 193 (62,9\% del total) se localizan en las áreas de pastos, lo que representa una concentración de 28,9 deslizamientos por $\mathrm{km}^{2}$. Además otras 76 cicatrices $(24,8 \%)$ aparecen en las áreas erosionadas, es decir, en los bordes de pequeños restos de suelo que aún no han sido erosionados y que son difícilmente cartografiables por su tamaño. Estas áreas erosionadas son, evidentemente, la consecuencia de la erosión de zonas que anteriormente estuvieron ocupadas por pastos subalpinos y, previamente, por bosque (ver, por ejemplo, la Figura 4). Así lo sugieren no sólo los restos de sue- 


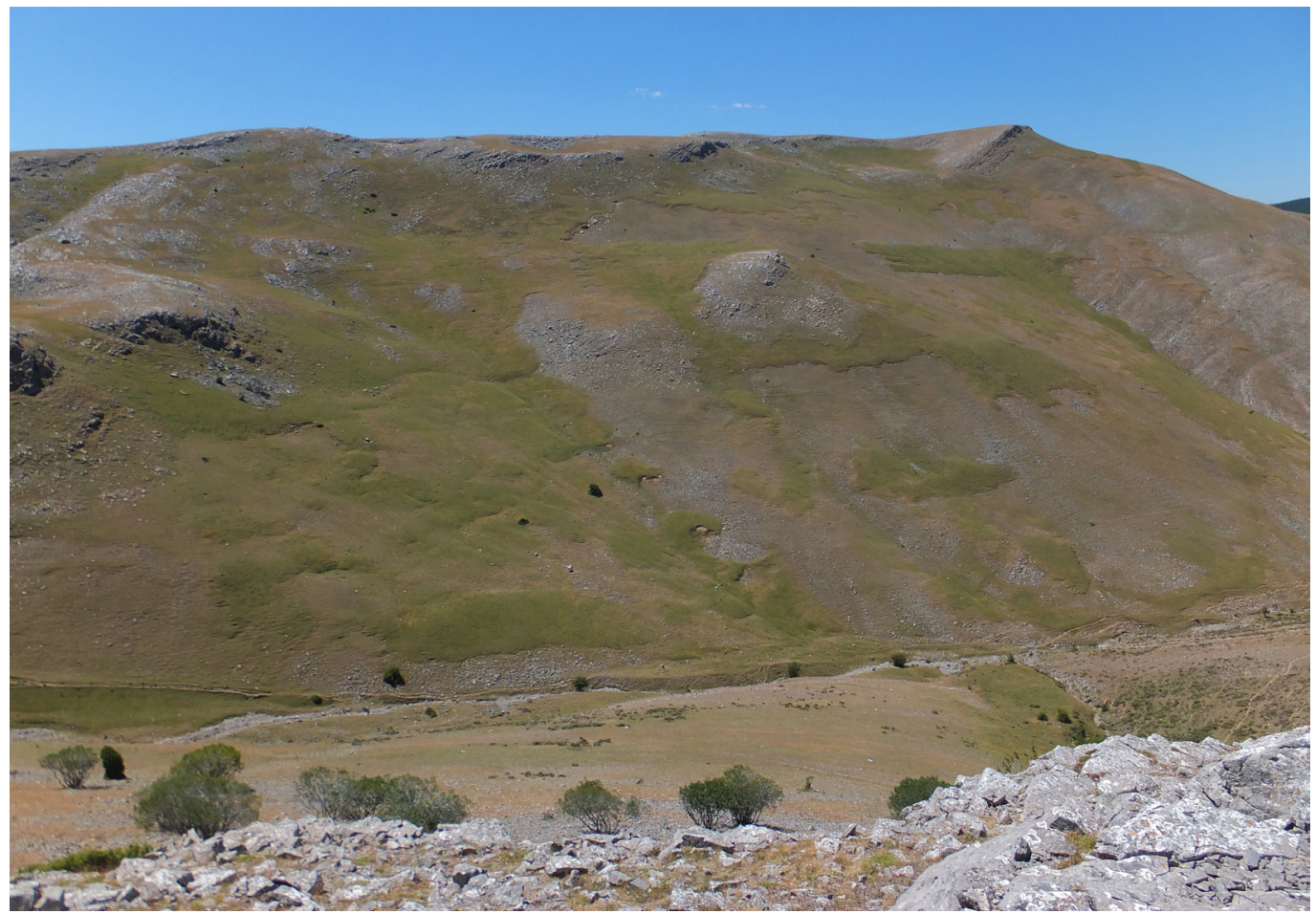

Figura 3: La deforestación provocó la desestabilización de las laderas en la Sierra de Urbión, que evolucionan mediante procesos lentos de solifluxión o deslizamientos superficiales más rápidos. Parte del suelo ha sido ya erosionado.

Figure 3: Deforestation resulted in instability of the slopes in the Urbión Sierra, evolving by means of slow solifluction processes and shallow landslides. Part of the soil has been already eroded.

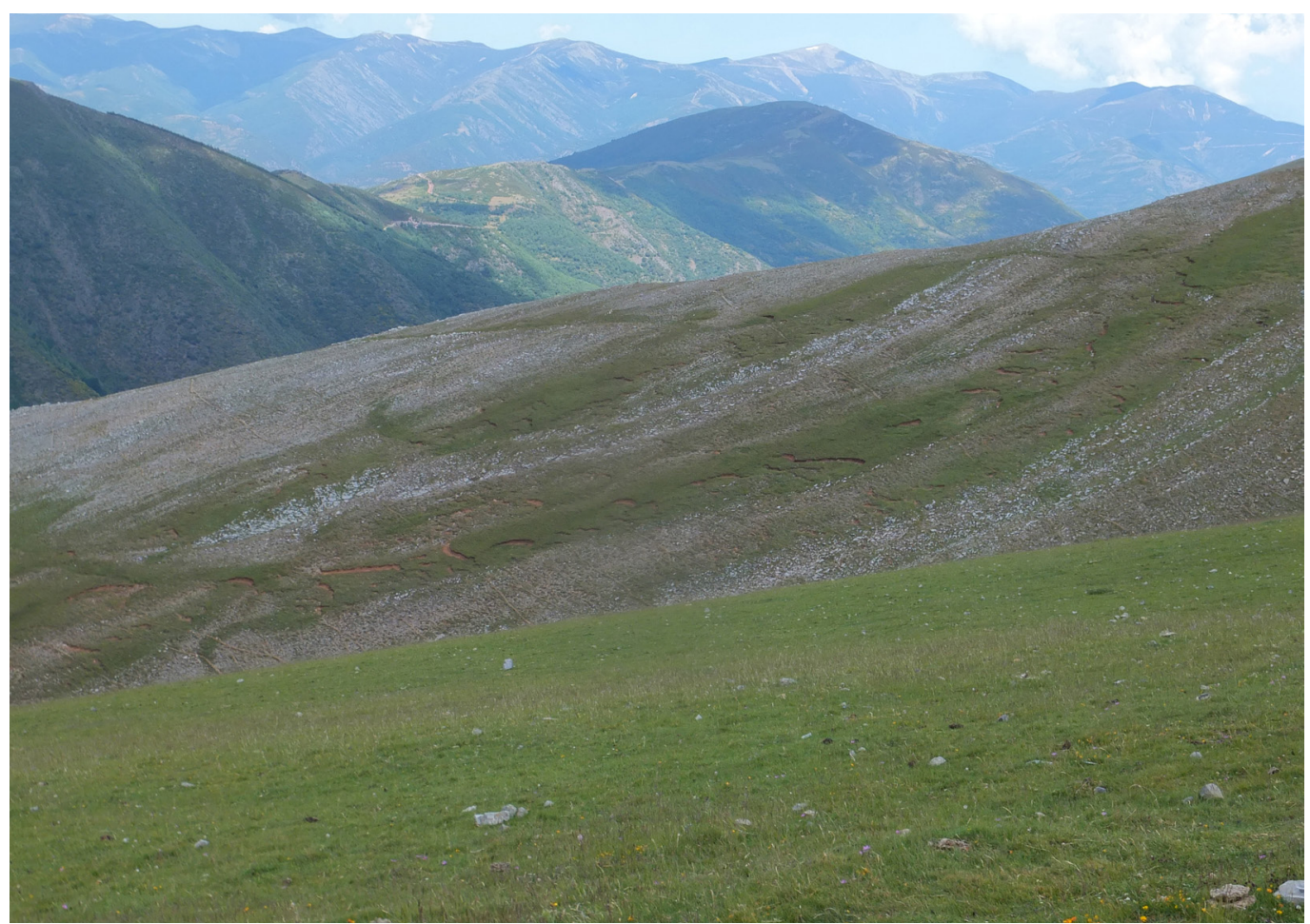

Figura 4: En segundo plano, alternancia de restos de suelo intensamente afectados por deslizamientos superficiales y áreas ya erosionadas. Figure 4: Remnants of soil intensively affected by shallow landslides alternate with already eroded areas. 


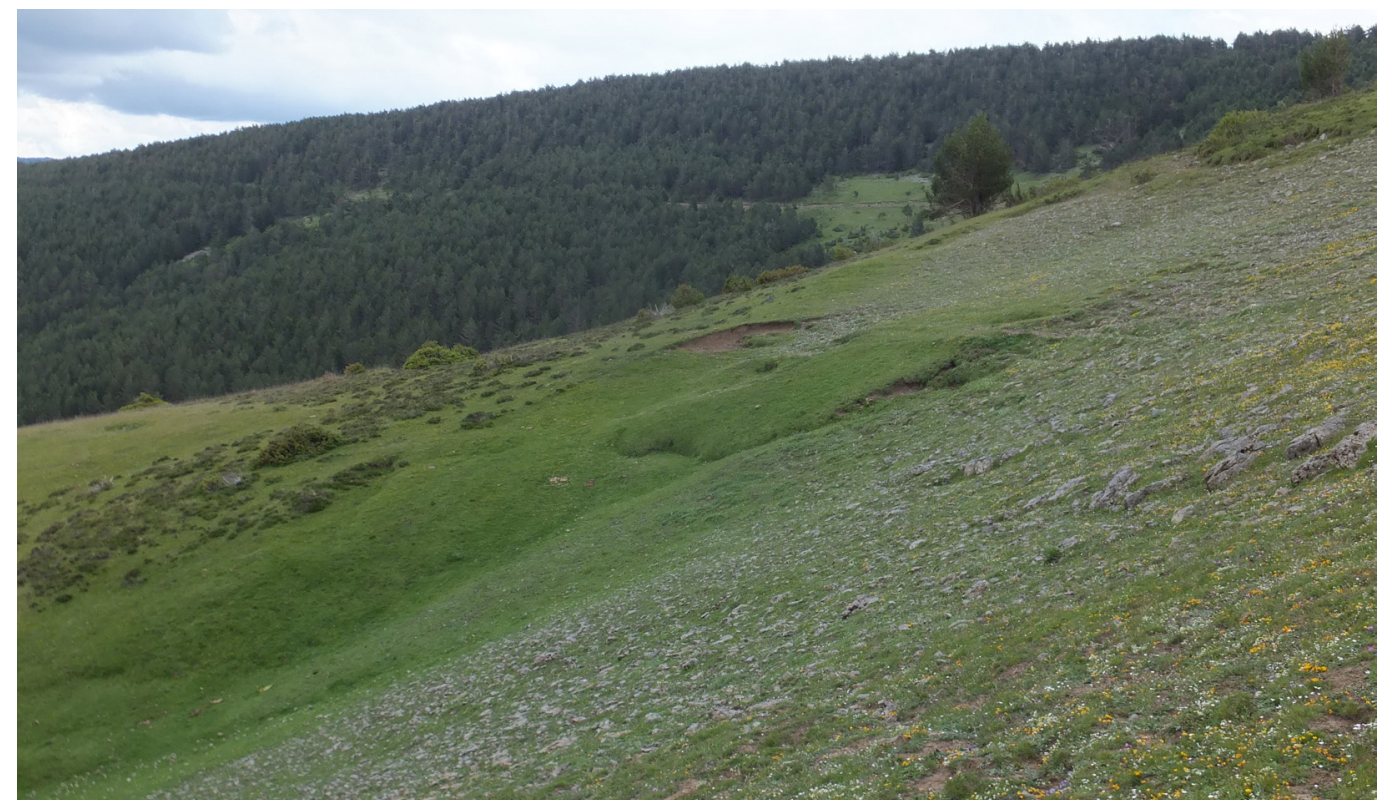

Figura 5: Esta imagen representa una síntesis del paisaje actual en el piso subalpino de la Sierra de Urbión y su evolución reciente. Al fondo, pinares de pino silvestre en la cabecera del valle de Ormazal, que se han extendido de forma natural en los últimos 50 años tras la disminución de la presión ganadera. En segundo plano, dos de las geoformas más frecuentes en el piso subalpino deforestado: lóbulo de solifluxión y cicatriz de deslizamiento superficial. En primer plano, sustrato rocoso tras el desmantelamiento del suelo por deslizamientos superficiales.

Figure 5: This picture represents a synthesis of the present landscape in the subalpine belt of the Urbion Sierra and its recent evolution. On the horizon, Pinus sylvestris forest has colonized the headwater of the Ormazal Valley in the last 50 years. Solifluction lobes and shallow landslide scars are two of the most frequent landforms in the subalpine belt after deforestation. In the foreground, bedrock appears after soil erosion because of shallow landslides.

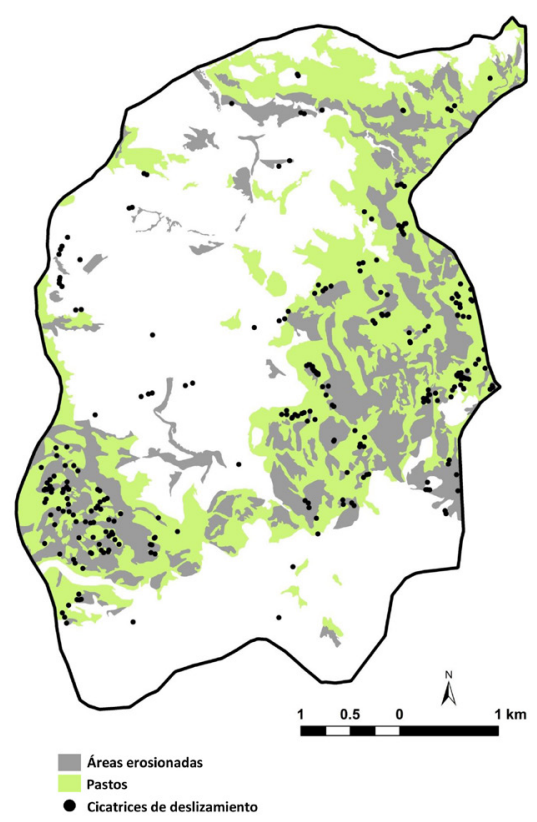

Figura 6: Distribución de los pastos subalpinos y áreas erosionadas en el valle de Ormazal a partir de las ortofotos de 2006. Se incluye también la localización de las cicatrices de deslizamientos superficiales.

Figure 6: Spatial distribution of subalpine grasslands and eroded areas in the Ormazal Valley from the orthophotos of 2006. The location of the shallow landslide scars has been also included. lo profundo que están afectados por deslizamientos, sino también el hecho de que tanto los pastos subalpinos como las áreas erosionadas responden a las mismas signaturas topográficas (altitud, especialmente). Por lo tanto, si se consideran conjuntamente los deslizamientos de los pastos subalpinos y los de las áreas erosionadas, sumarían en total 269 cicatrices, que representan el $87,7 \%$ de los deslizamientos cartografiados en el valle. Los deslizamientos en matorral son $27(8,8 \%)$ y sólo $5(1,6 \%)$ se localizan en bosque (Tabla 1). Es evidente, por lo tanto, la estrecha relación entre deforestación y deslizamientos en el piso subalpino (García-Ruiz et al., 2016; Beguería et al., en-

Tabla 1: Distribución de deslizamientos superficiales según la cubierta vegetal.

Table 1: Shallow landslides distribution according to plant cover.

\begin{tabular}{|l|c|c|}
\hline \multicolumn{1}{|c|}{ Usos del suelo } & Frecuencia & Porcentaje \\
\hline Bosque Claro & 1 & $0,3 \%$ \\
\hline Bosque Denso & 8 & $2,6 \%$ \\
\hline Áreas erosionadas & 78 & $25,4 \%$ \\
\hline Matorral & 27 & $8,8 \%$ \\
\hline Pastos & 193 & $62,9 \%$ \\
\hline Total & 307 & $100,0 \%$ \\
\hline
\end{tabular}


viado). En este último trabajo citado puede encontrarse más información sobre los factores que en mayor medida inducen al desarrollo de deslizamientos, incluyendo algunas características de los suelos.

\section{Discusión y conclusiones: Una perspectiva geoecológica}

Los recientes estudios llevados a cabo en la Sierra de Urbión (García-Ruiz et al., 2016; Beguería et al., enviado; Sanjuán et al., enviado) reflejan los profundos cambios que han ocurrido en el piso subalpino desde un punto de vista paisajístico y de la gestión del territorio. Tales cambios reflejan una concepción bien diferente de la tradicional acerca del aprovechamiento de la diversidad del territorio y de sus complementariedades, y tienen notables repercusiones ambientales, algunas de las cuales son bien conocidas. En todo caso, se trata de un ejemplo excelente que revaloriza la perspectiva geoecológica de ambientes intensamente intervenidos por actividades humanas, y en los que la naturaleza tiene una elevada capacidad de reacción o resiliencia. Es también una prueba más de que desde la Geomorfología, como ciencia global (García-Ruiz, 2015), se pueden reinterpretar los cambios paisajísticos y sus efectos a diferentes escalas espacio-temporales.

La Sierra de Urbión, como otras montañas mediterráneas y alpinas, fue tempranamente explotada por la ganadería, provocando la transformación de los bosques de los pisos subalpino y montano superior, por encima de 1550 m s.n.m., en extensas áreas de pastos que pudieran aprovecharse durante el verano. Eso favoreció la introducción de sistemas trasterminantes (de corto recorrido, entre el fondo de los valles y las cumbres) y trashumantes (de recorrido más largo, complementando los recursos altimontanos y los de las tierras bajas) desde el Neolítico tardío. La construcción de ese paisaje de pastos subalpinos fue seguramente más compleja de lo que imaginamos, con sucesivos avances y retrocesos del bosque y de los pastos en función de la presión ganadera y del número de habitantes, así como de la evolución del mercado de la lana. Muy probablemente, la presión ganadera no fue muy intensa al principio y eso explica el que la utilización del fuego para eliminar el bosque fuera un procedimiento recurrente a lo largo del Calcolítico y las edades del Bronce y del Hierro. El hecho de haber encontrado una sola evidencia de incendio en el piso subalpino durante la Edad Media y ninguna durante la Edad Moderna sugiere que en esos momentos los pastos de aprovechamiento estival ya dominarían en las partes más elevadas de la sierra y que un aumento de la presión ganadera conduciría a eliminar el bosque en parte del piso montano, donde no se ha realizado ninguna prospección. Es sólo una hipótesis, pero parece muy probable que la gran carga ganadera soportada por la Sierra de Urbión desde el siglo XV al siglo XIX sólo pudiera admitirse ampliando la superficie de pastos hacia el piso montano superior. En todo caso, los sedimentos acumulados en las lagunas Nava y Ciega en las proximi- dades de la vecina Sierra Cebollera reflejan el retroceso temprano del bosque y la presencia de numerosos fragmentos de carbones indicadores de la ocurrencia de incendios (Gil García et al., 1996). En la laguna de Hornillo, Sierra de Urbión, Gómez-Lobo (1993) detectó un descenso de polen arbóreo desde $4500 \mathrm{BP}$, aunque no explica si se debe o no a influencia humana.

Se sabe también que la transformación del bosque subalpino en pastos tuvo elevados costes ambientales, especialmente desde un punto de vista geomorfológico, como consecuencia del efecto del fuego sobre las características del suelo (Zavala et al., 2014; Keizer et al., 2015) y su estabilidad. El más destacado es la ocurrencia de un elevado número de deslizamientos superficiales que desmantelaron un suelo rico y relativamente profundo en las laderas más pendientes, como ya se había observado en el Pirineo centro-occidental (GarcíaRuiz et al., 2010). La pérdida de cohesión de suelo unida a una mayor disponibilidad de agua en unos suelos con un bajo índice de plasticidad (Beguería et al., enviado), favorecieron la inestabilidad y la formación de cicatrices acompañadas de terracillas de gelifluxión, lóbulos de solifluxión y, en determinados casos (laderas pendientes), la formación de incisiones paralelas y cabeceras activas de torrentes (García-Ruiz \& Puigdefábregas, 1982). En algunos valles pirenaicos, en los que la deforestación pudo llegar hasta tiempos relativamente recientes (siglo XIX, como, por ejemplo, en el valle de Ijuez) la actividad geomorfológica provocó el relleno del fondo del valle con sedimentos muy gruesos, transportados mediantes flujos de derrubios (Gómez-Villar et al., 2014; Sanjuán et al., 2016), mientras el piso subalpino aparece parcialmente incidido por barranqueras muy activas. Las evidencias geomorfológicas de la deforestación se han comprobado también con el estudio de los sedimentos acumulados en lagos y turberas y la presencia de niveles de cenizas que preceden a una reactivación de la sedimentación de materiales detríticos, indicadores de procesos erosivos (Montserrat, 1992). La erosión en los pastos subalpinos en la Sierra de Urbión explica la relativamente elevada extensión ocupada por las áreas erosionadas (más del 17\% de la superficie en el valle de Ormazal), que coinciden espacialmente (misma altitud, aunque mayor pendiente) con las áreas de pastos.

La crisis de la trashumancia y el consiguiente retroceso de los censos ganaderos es la razón por la que las especies leñosas (matorrales y pinares) están ahora en plena expansión, mitigada en parte porque todavía quedan unos pocos rebaños de ganado lanar pastando en verano y por la presencia de un mayor número de cabezas de ganado vacuno (Montserrat, 2009; García-Ruiz, 2009b). Lo cierto es que la recuperación de los pinares es relativamente temprana, desde comienzos del siglo XIX, tal como detectó Gómez-Lobo (1993) en la laguna de Hornillo, coincidiendo con el inicio de la crisis de la trashumancia (Moreno Fernández, 1994). La expansión del bosque ha hecho que en la vertiente meridional de la Sierra de Urbión la treeline haya experimentado un avance altitudinal de más 
de $50 \mathrm{~m}$ de media en los últimos 50 años (García de Celis et al., 2008), sobre todo en laderas rectilíneas o algo convexas, mientras el avance es más lento en las concavidades por la presencia más prolongada de la nieve. Dichos autores también han comprobado una contracción de los pastos subalpinos de hasta un $23 \%$ en la vertiente sur. La reducción de los censos de ganado lanar y caprino sería, una vez más, la razón más importante de la tendencia a la lignificación. No debe descartarse una cierta influencia del incremento térmico reciente, que favorecería la germinación de las semillas de pino y reduciría la permanencia de nieve en la parte alta de la montaña. De hecho, García de Celis et al. (2008) estimaron que en todas las estaciones de la vertiente sur se habría producido un aumento medio de $1,1^{\circ} \mathrm{C}$ en la temperatura media anual, y algo mayor $\left(1,3^{\circ} \mathrm{C}\right)$ en la temperatura de los meses invernales. La influencia de esta evolución térmica junto con algunos cambios en la distribución estacional de las precipitaciones tiene repercusiones dramáticas sobre la duración del manto de nieve, tal como han demostrado LópezMoreno (2005) y López-Moreno et al. (2009) en el Pirineo Central. Desconocemos cuál es el impacto de la menor innivación en la dinámica de los deslizamientos superficiales. Se sabe por estudios en el Pirineo Central (García-Ruiz et al., 2010) que tales deslizamientos ocurren coincidiendo con eventos pluviométricos de baja frecuencia y durante periodos de fusión de nieve. La menor acumulación de nieve en el piso subalpino a finales del invierno así como también la creciente magnitud y frecuencia de periodos secos sugerida por diversos estudios (Gouveia et al., 2016; Vicente-Serrano, 2016) podrían reducir la ocurrencia de deslizamientos, si bien la incertidumbre en este sentido es muy grande. Aunque no se tiene información acerca del momento de mayor actividad de los deslizamientos en el piso subalpino, García-Ruiz et al. (2010) sugieren que el mayor impacto geomorfológico de la deforestación ocurrió durante la Edad Moderna, cuando la extensión del bosque alcanzaría sus valores mínimos, coincidiendo además con la Pequeña Edad del Hielo (siglos XVI-XIX), caracterizada por una mayor innivación y probablemente precipitaciones más extremas (Benito et al., 2008). Es seguro, no obstante, que los deslizamientos superficiales y la erosión del suelo comenzasen con las primeras deforestaciones desde el Neolítico, como demuestran Guiguet-Covex et al. (2011) en los Alpes.

La lignificación del piso subalpino en la Sierra de Urbión tiene otras consecuencias importantes. Es evidente que los cambios paisajísticos que se observan en las últimas décadas representan cambios en los servicios ecosistémicos que el piso subalpino presta a la sociedad y al funcionamiento ecológico de las áreas de montaña como sistemas complejos (Montserrat, 2009; Gartzia et al., 2014), incluyendo la colonización (o mayor éxito) por parte de nuevas especies florísticas y faunísticas y quizás la expulsión de otras. La expansión del bosque continuará en el futuro, especialmente en las áreas de matorral, y de manera más lenta en los pastos subalpinos, dando lugar a una progresiva homogeneización del paisaje.

\section{Agradecimientos}

La elaboración de este trabajo ha contado con el apoyo del proyecto ESPAS, CGL2015-65569-R (MINECO-FEDER).

\section{Referencias}

Arnáez Vadillo, J., 1987. Formas y procesos en la evolución de vertientes de la Sierra de la Demanda (Sistema Ibérico). Cuadernos de Investigación Geográfica, 13: 7-153. http:// dx.doi.org/10.18172/cig.962.

Bal, M.C., Pelachs, A., Perez-Obiol, R., Julia, R. \& Cunill, R., 2011. Fire history and human activities during the last 3300 cal yr BP in Spain's Central Pyrenees: The case of the Estany de Burg. Palaeogeography, Palaeoclimatology, Palaeoecology, 300 (1-4): 179-190. Doi: 10.1016/j.palaeo.2010.12.023.

Beguería, S., Sanjuán, Y., Arnáez, J., Gómez-Villar, A., ÁlvarezMartínez, J., Lana-Renault, N., Coba-Pérez, P. \& Pérez-Cardiel, E., enviado. Early deforestation induces shallow landsliding in the montane/subalpine belts of the Urbión Mountains, Iberian Range, Northern Spain. Geomorphology.

Benito, G., Thorndycraft, V.R., Rico, M., Sánchez-Moya, Y \& Sopeña, A., 2008. Palaeoflood and floodplain records from Spain: Evidence for long-term climate variability and environmental changes. Geomorphology, 101 (1-2): 68-77. Doi: 10.1016/j.geomorph.2008.05.020.

Blarquez, O., Carcaillet, C., Bremond, L., Mourier, B. \& Radakovitch, O., 2010. Trees in the subalpine belt since $11700 \mathrm{cal}$ BP: origin, expansion and alteration of the modern forest. The Holocene, 20: 139-146. Doi: 10.1177/0959683609348857.

Calvo Palacios, J.L. 1977. Los Cameros. De región homogénea a espacio plan. Instituto de Estudios Riojanos, 298 pp., Logroño.

Colombaroli, D., Henne, P.D., Kaltenrieder, P., Gobet, E. \& Tinner, W., 2010. Species responses to fire, climate and human impact at tree line in the Alps as evidenced by palaeo-environmental records and a dynamic simulation model. Journal of Ecology, 98: 1346-1357. Doi: 10.1111/j.1365-2745.2010.01723.x.

Colombaroli, D., Beckmann, M., van der Knaap, W.O., Curdy, P. \& Tinner, W., 2013. Changes in biodiversity and vegetation composition in the central Swiss Alps during the transition from pristine forest to first farming. Diversity and Distributions, 19: 157-170. Doi: 10.1111/j.1472-4642.2012.00930.x.

Daumas, M., 1976. La vie rurale dans le Haut Aragon Oriental. Instituto de Geografía Aplicada, Madrid, 774 pp.

Diago Hernando, M., 2002. Mesta y trashumancia en Castilla (siglos XIII a XIX). Madrid, Arco Libros, 96 pp.

Esteva Fabregat, C., 1971. Para una teoría de la aculturación en el Alto Aragón. Ethnica, 2: 9-78.

Galop, D. \& Jalut, G., 1994. Differential human impact and vegetation history in two adjacent Pyrenean valleys in the Ariège basin, southern France, from 3000 BP to the present. Vegetation History and Archaeobotany, 3: 225-244. Doi: 10.1007/BF00195199.

García de Celis, A., Arroyo Pérez, P. \& Gandía Fernández, A., 2008. Cambios recientes del límite superior del bosque en Urbión: gestión forestal, ganadería y clima. Zubía Monográfico, 20: 97-118.

García-Ruiz, J.M., 1976. Modos de vida y niveles de renta en el Prepirineo del Alto Aragón Occidental. Instituto de Estudios Pirenaicos, 272 pp., Jaca.

García-Ruiz, J.M., 2009a. Las sierras de Cameros en el contexto de las montañas españolas: de la complejidad al desmoronamiento. En: Gestión, usos del suelo y paisaje en Cameros, Sistema Ibérico, La Rioja (T. Lasanta y J. Arnáez, eds.), 
Instituto de Estudios Riojanos y Universidad de La Rioja, Logroño, pp. 355-373.

García-Ruiz, J.M., 2009b. Los Cameros, casi cuarenta años después: entre la integración y la marginación. Zubia, 27: $159-176$.

García-Ruiz, J.M., 2015. Why Geomorphology is a global science. Cuadernos de Investigación Geográfica, 41 (1): 87 105. Doi:10.18172/cig.2652.

García-Ruiz, J.M. \& Puigdefábregas, J., 1982. Formas de erosión en el flysch eoceno surpirenaico. Cuadernos de Investigación Geográfica, 8: 85-130. Doi: 10.18172/cig.897.

García-Ruiz, J.M. \& Lasanta, T., 1993. Land-use conflicts as a result of land-use change in the Central Spanish Pyrenees: A review. Mountain Research and Development, 13 (3): 295304. Doi: 10.2307/3673658

García-Ruiz, J.M., Alvera, B., Del Barrio, G. \& Puigdefábregas, J., 1990. Geomorphic processes above timberlinein the Spanish Pyrenees. Mountain Research and Development, 10 (3): 201-214.

García-Ruiz, J.M., Ortigosa, L., Pellicer, F. \& Arnáez, J., 1998. Geomorfología glaciar del Sistema Ibérico. En: Las huellas glaciares de las montañas españolas (A. Gómez Ortiz \& A. Pérez Alberti, eds.), Universidad de Santiago de Compostela, Santiago de Compostela, pp. 347-381.

García-Ruiz, J.M., Beguería, S., Alatorre, L.C. \& Puigdefábregas, J., 2010. Land cover changes and shallow landsliding in the flysch sector of the Spanish Pyrenees. Geomorphology, 124 (3-4): 250-259. Doi: 10.1016/j.geomorph.2010.03.036.

García-Ruiz, J.M., López-Moreno, J.I., Lasanta, T., Vicente-Serrano, S.M., González-Sampériz, P., Valero-Garcés, B.L., Sanjuán, Y., Beguería, S., Nadal-Romero, E., Lana-Renault, N. \& Gómez-Villar, A., 2015. Los efectos geoecológicos del Cambio Global en el Pirineo Central español: una revisión a distintas escalas espaciales y temporales. Pirineos, 170, e012. Doi: 10.3989/Pirineos.2015.170005.

García-Ruiz, J.M., Sanjuán, Y., Gil-Romera, G., González-Sampériz, P., Beguería, S., Arnáez, J., Coba-Pérez, P., GómezVillar, A., Álvarez-Martínez, J., Lana-Renault, N., PérezCardiel, E. \& López de Calle, C., 2016. Mid and Late Holocene forest fires and deforestation in the Subalpine belt of the Iberian Range, Northern Spain. Journal of Mountain Science.

Gartzia, M., Alados, C.L. \& Pérez-Cabello, F., 2014. Assessment of the effects of biophysical and anthropogenic factors on woody plant encroachment in dense and sparse mountain grasslands based on remote sensing data. Progress in Physical Geography, 38 (2): 201-217. Doi: 10.1177/0309133314524429.

Gartzia, M., Pérez-Cabello, F., Bueno, C.G. \& Alados, C.L., 2016. Physiognomic and physiologic changes in mountain grasslands in response to environmental and anthropogenic factors. Applied Geography, 66: 1-11. Doi: 10.1016/J. apgeog.2015.11.007.

Gil García, M.J., Tomás Las Heras, R., Núñez Olivera, E., Martínez Abaigar, J., 1995. Análisis polínico de un depósito higroturboso de la Sierra de Cameros (La Rioja, España). $\mathrm{Zu}$ bía Monográfico, 13: 33-41.

Gil García, M.J., Tomás de Las Heras, R., Núñez Olivera, E., Martínez Abaigar, J., 1996. Acción humana sobre el medio natural en la Sierra de Cameros a partir del análisis polínico. Zubia Monográfico, 8: 29-41.

Gil García, M.J., Dorado Valiño, M., Valdeolmillos Rodríguez, A., Ruiz Zapata, M.B., 2002. Late-glacial and Holocene palaeoclimatic record from Sierra Cebollera (Northern Iberian Range, Spain). Quaternary International, 93-94: 13-18. Doi: 10.1016/S1040-6182(02)00003-4.

Gómez-Lobo, A., 1993. Historia de la vegetación durante los últimos 15.000 años en los Picos de Urbión (Soria) en base al análisis polínico. Tesis Doctoral inédita, Universidad de Alcalá de Henares, 173 pp., Alcalá de Henares.

Gómez-Villar, A., Sanjuán, Y., García-Ruiz, J.M., Nadal-Romero, E., Álvarez-Martínez, J., Arnáez, J., Serrano Muela, M.P., 2014. Sediment organization and adjustment in a torrential reach of the Upper Ijuez River, Central Spanish Pyrenees. Cuadernos de Investigación Geográfica, 40 (1): 191-214. Doi: 10.18172/cig.2566.

Gouveia, C.M., Páscoa, P., Russo, A. \& Trigo, R.M., 2016. Land degradation trend assessment over Iberia during 1982-2012. Cuadernos de Investigación Geográfica, 42 (1): 89-112. http://dx.doi.org/10.18172/cig.2945.

Guiguet-Covex, C., Arnaud, F., Poulenard, J., Disnar, J.R., Delhon, C., Francus, P., David, F., Enters, D., Rey, P.J. \& Delannoy, J.J., 2011. Changes in erosion patterns during the Holocene in a currently treeless subalpine catchment inferred from lake sediment geochemistry (Lake Anterne, $2063 \mathrm{~m}$ a.s.l., NW French Alps): The role of climate and human activities. The Holocene, 21(4): 651-665. Doi:10.1177/0959683610391320.

Höllermann, P., 1985. The periglacial belt of mid-latitude mountains from a geoecological point of view. Erdkunde, 39 (4): 259-270. Doi: 10.3112/erdkunde.1985.04.02.

Keizer, J.J., Martins, M.A.S., Prats, S.A., Faria, S.R., GonzálezPelayo, O., Machado, A.I., Rial-Rivas, M.E., Santos, L.F., Serpa, D. \& Varela, M.E.T., 2015. Within-in flume sediment deposition in a forested catchment following wildfire and postfire bench terracing, North-Central Portugal. Cuadernos de Investigación Geográfica, 41 (1): 149-164. Doi: 10.18172/ cig. 2700 .

Lasanta, T., 1989. Evolución reciente de la agricultura de montaña: el Pirineo aragonés. Geoforma Ediciones, 220 pp., Logroño.

Lasanta, T., 1990. Diversidad de usos e integración espacial en la gestión tradicional del territorio en las montañas de Europa Occidental. En: J.M. García-Ruiz, Geoecología de las áreas de montaña, Geoforma Ediciones, Logroño, pp. 235-266.

Lasanta, T., 2014. El paisaje de campos abandonados en Cameros Viejo (Sistema Ibérico, La Rioja). Instituto de Estudios Riojanos, 305 pp., Logroño.

Lasanta, T., Beguería, S. \& García-Ruiz, J.M., 2006. Geomorphic and hydrological effects of traditional shifting agriculture in a Mediterranean mountain area, Central Spanish Pyrenees. Mountain Research and Development, 26 (2): 146152. Doi: http://dx.doi.org/10.1659/0276-4741(2006)26[146:GA HEOT]2.0.CO;2.

López de Calle, C. \& Pérez Arrondo, C., 1995. Fechas de radiocarbono y fases de ocupación en los sepulcros megalíticos de Cameros (La Rioja). Istúriz: Prehistoria-Arqueología, 6: 343-360.

López de Calle, C. \& Tudanca, J.M., 2014. Contemplando Cameros desde la Arqueología: actitudes y planteamientos metodológicos en la interpretación del paisaje. Berceo, 167: 121-176.

López de Calle, C., Iriarte, M.J., Zapata, L., 2001. Análisis paleoambientales en el dolmen del Collado del Mallo (Trevijano, La Rioja). Viabilidad y trabas de la paleoecología vegetal en estructuras dolménicas. Zubía Monográfico, 13: 65-96.

López-Moreno, J.I., 2005. Recent variations of snowpack depth in the Central Spanish Pyrenees. Arctic, Antarctic, and Alpine Research, 37 (2): 253-260. http://dx.doi.org/10.1657/15230430(2005)037[0253:RVOSDI]2.0.CO;2.

López-Moreno, J. I., Goyette, S. \& Beniston, M., 2009. Impact of climate change on snowpack in the Pyrenees: Horizontal spatial variability and vertical gradients. Journal of Hydrology, 374 (3-4): 384-396. Doi: 10.1016/j.jhydrol.2009.06.049.

Miras, Y., Ejarque, A., Riera, S., Palet, J.M., Orengo, H. \& Euba, I., 2007. Dynamique holocène de la végétation et occupation 
des Pyrénées andorranes depuis le Néolithique ancien, d'après l'analyse pollinique de la tourbière de Bosc dels Estanyons (2180 m, Vall del Madriu, Andorre). Comptes Rendus Palevol, 6 (4): 291-300. Doi: 10.1016/j.crpv.2007.02.005.

Miras, Y., Ejarque, H., Orengo, H., Mora, S.R., Palet, J.M. \& Poiraud, A., 2010. Prehistoric impact on landscape and vegetation at high altitudes: An integrated palaeoecological and archaeological approach in the Eastern Pyrenees (Perafita valley, Andorra). Plant Biosystems, 144 (4): 924-939. http://dx.doi.org/10.1080/11263504.2010.491980.

Montserrat, J., 1992. Evolución glaciar y postglaciar del clima y la vegetación en la vertiente sur del Pirineo: Estudio palinológico. Instituto Pirenaico de Ecología, 147 pp., Zaragoza.

Montserrat, P., 2009. La cultura que hace el paisaje. La Fertilidad de la Tierra Ediciones, 237 pp., Estella.

Moreno Fernández, J.R., 1994. El monte público en La Rioja durante los siglos XVIII y XIX: aproximación a la desarticulación del régimen comunal. Logroño, Gobierno de La Rioja, 299 pp., Logroño.

Moreno Fernández, J .R., 1996. La ganadería trashumante en La Rioja 1752-1865. Una revisión bibliográfica y cuantitativa. Brocar, 20: 277-302.

Pérez-Sanz, A., González-Sampériz, P., Moreno, A., ValeroGarcés, B., Gil-Romera, G., Rieradevall, M., Tarrats, P., Lasheras-Álvarez, L., Morellón, M., Belmonte, A., Sancho, C., Sevilla-Callejo, M. \& Navas, A., 2013. Holocene climate variability, vegetation dynamics and fire regime in the central Pyrenees: the Basa de la Mora sequence (NE Spain). Quaternary Science Reviews, 73: 149-169. Doi: 10.1016/j. quascirev.2013.05.010.

Puigdefábregas, J. \& Balcells, E., 1966. Resumen sobre el régimen de explotación ovina trashumante en el Alto Aragón, especialmente en el valle de Ansó. Publicaciones del Centro Pirenaico de Biología Experimental, 1 (6): 1-18.

Puigdefábregas, J. \& Balcells, E., 1970. Relaciones entre la organización social y la explotación del territorio en el valle de El Roncal (Navarra oriental). Pirineos, 98: 53-89.

Puigdefábregas, J. \& Fillat, F., 1986. Ecological adaptation of traditional land use in the Spanish Pyrenees. Mountain Research and Development, 6 (1): 63-72.

Pujadas, J.J. \& Comas, D., 1975. La casa en el proceso de cambio del Pirineo aragonés. Cuadernos de Investigación (Geografia e Historia), 2: 51-62.

Reimer, P.J., Bard, E., Bayliss, A., Beck, J.W., Blackwell, P.G., Ramsey, C.B., Buck, C.E., Cheng, H., Edwards, R.L., Friedrich, M., Grootes, P.M., Guilderson, T.P., Haflidason, H., Hajdas, I., Hatté, C., Heaton, T., Hoffmann, D.L., Hogg, A.G., Hughen, K.A., Kaiser, K.F., Kromer, B., Manning,
S.W., Niu, M., Reimer, R.W., Richards, D.A., Scott, E.M., Southon, J.R., Staff, R.A., Turney, C.S.M. \& van der Plicht, J., 2013. INTCAL13 and Marine13 radiocarbon age calibration curves 0-50,000 years cal BP. Radiocarbon, 55 (4): 1869-1887. Doi: 10.2458/azu js_rc.55.16947.

Rodríguez Pascual, M., 2004. La trashumancia. Cultura, cañadas y viajes. Edilesa, León, $460 \mathrm{pp}$.

Roepke, A. \& Krause, R., 2013. High montane-subalpine soils in the Montafon Valley (Austria, northern Alps) and their link to land-use, fire and settlement history. Quaternary International, 308-309: 178-189. Doi: 10.1016/j.quaint.2013.01.022.

Ruiz-Flaño, P., 1993. Procesos de erosión en campos abandonados del Pirineo. Geoforma Ediciones, 191 pp., Logroño.

Sanjuán, Y., Gómez-Villar, A., Nadal-Romero, E., Álvarez-Martínez, J., Arnáez, J., Serrano-Muela, M.P., Rubiales, J.M., González-Sampériz, P. \& García-Ruiz, J.M., 2016. Linking land cover changes in the subalpine and montane belts to changes in a torrencial river. Land Degradation \& Development, 27: 179-189. Doi: 10.1002/ldr.2294.

Sanjuán, Y., Arnáez, J., Beguería, S., Lana-Renault, N., Lasanta, T., Gómez-Villar, A., Álvarez-Martínez, J., Coba-Pérez, P. \& García-Ruiz, J.M., enviado. Woody plant encroachment following land abandonment in the upper montane and subalpine belts of the Urbión Mountains, Iberian Range, Northern Spain. Landscape and Urban Planning.

Serrano-Muela, M.P., Lana-Renault, N., Nadal-Romero, E., Regüés, D., Latron, J., Martí-Bono, C. \& García-Ruiz, J.M., 2008. Forests and their hydrological effects in Mediterranean mountains: The case of the Central Spanish Pyrenees. Mountain Research and Development, 28 (3-4): 279-285. Doi: $10.1659 / \mathrm{mrd} .0876$.

Stuiver, M. \& Reimer, P.J., 1993. Extended 14C data base and revised CALIB 3.0 $14 \mathrm{C}$ age calibration program. Radiocarbon, 35 (1): 215-230.

Tinner, W., Lotter, A.F., Ammann, B., Conedera, M., Hubschmid, P., van Leeuwen, J.F.N. \& Wehrli, M., 2003. Climatic change and contemporaneous land-use phases north and south of the Alps 2300 BC to 800 AD. Quaternary Science Reviews, 22 (14): 1447-1460. Doi: 10.1016/S0277-3791(03)00083-0.

Tischer, G., 1966. El delta weáldico de las montañas ibéricas occidentales y sus enlaces tectónicos. Notas y Comunicaciones del IGME, 81: 53-78.

Vicente-Serrano, S.M., 2016. Foreword: Drought complexity and assessment under climate change conditions. Cuadernos de Investigación Geográfica, 42 (1): 7-11. Doi: 10.18172/ cig. 2961

Zavala, L.M., de Celis, R. \& Jordán, A., 2014. How wildfires affect soil properties. A brief review. Cuadernos de Investigación Geográfica, 40 (2): 311-331. Doi: 10.18172/cig.2522. 